\title{
Role and Risk Factors of Glycosylated Hemoglobin Levels in Early Disease Screening
}

\author{
Guanqun Chao $\mathbb{D}$, Yue Zhu, and Liying Chen \\ Department of General Practice, Sir Run Run Shaw Hospital, Zhejiang University, China \\ Correspondence should be addressed to Liying Chen; 3197020@zju.edu.cn
}

Received 7 December 2020; Revised 18 March 2021; Accepted 30 March 2021; Published 8 April 2021

Academic Editor: Ashraf El-Metwally

Copyright @ 2021 Guanqun Chao et al. This is an open access article distributed under the Creative Commons Attribution License, which permits unrestricted use, distribution, and reproduction in any medium, provided the original work is properly cited.

\begin{abstract}
Objective. To clarify the correlation among glycosylated hemoglobin ( $\mathrm{HbAlc})$, gender, age, fatty liver, and biochemical indicators through the analysis of big database, and to further investigate the risk factors affecting HbAlc, so as to lay a foundation for the study of HbAlc-related diseases and disease management. Methods. People who have been examined in Health Promotion Center from July 2018 to June 2019 were selected as the research objects. All data were analyzed using the Windows R software (version 3.5.1). Detailed medical history inquiry, laboratory examination, and B-ultrasound examination were carried out for the selected sample population. We determined the sample population according to the inclusion and exclusion criteria and, then, further grouped and analyzed the data. $T$-test or Mann-Whitney $U$ test was used for continuous variable comparison, and chisquare test was used to compare categorical variables. Logistic regression analysis was used to analyze the risk factors of HbAlc. Results. A total of 23,933 subjects were included in this study. The HbAlc level of men was significantly higher than that of women, the HbAlc level of the group with diabetes was higher than that of the group with no diabetes, and the HbAlc level of the group with fatty liver was higher than that of the group with no fatty liver. In the group with no diabetes, the HbA1c level increased with weight gain. Age, gender (male), fatty liver, waist circumference, systolic blood pressure (SBP), triglyceride (TG), blood urea nitrogen (BUN), free thyroxine (FT4), and red blood cell (RBC) were the risk factors for elevated HbA1c level, while high-density lipoprotein cholesterol (HDL-C), uric acid (UA), creatinine (Cr), free triiodothyronine (FT3), and hemoglobin were protective factors. Conclusion. Blood glucose, age, weight, gender, fatty liver, blood lipids, and UA are related to the increase of HbAlc level. HbAlc is related to many metabolic indexes and may be used as a marker for early detection of chronic diseases.
\end{abstract}

\section{Introduction}

With the development of economy, diabetes is affecting relatively wide portions of the world population, especially in developed countries, and the complications of diabetes are rising in younger people and earlier [1]. Obesity is an important risk factor of type 2 diabetes. With the improvement of living standards, the number of obese people increases gradually, causing the gradually mounting number of patients with diabetes, as well as the number of younger patients in particular [2]. There are nearly 180 million patients with diabetes in the world [3]. Glycosylated hemoglobin (HbAlc) plays an important role in the management of diabetes, which has been regarded as one of the most important research progress in the treatment of diabetes for decades
[4]. HbA1c has been used as an index for clinical diagnosis of diabetes in foreign countries. However, it is found that the threshold value of $\mathrm{HbAlc}$ is not suitable for young people, especially for Chinese people [5]. As we know, HbAlc reflects the average blood glucose of about three months, which is closely related to the complications of diabetes [6].

HbAlc is widely used in blood glucose management of gestational diabetes mellitus in addition to the clinical significance of $\mathrm{HbA} 1 \mathrm{c}$ for type 1 and type 2 diabetes mellitus [7]. HbAlc is affected by many other factors. The study shows that $\mathrm{HbAlc}$ is related to people's lifestyle, such as strenuous exercise and carbohydrate control [8]. It is well proved that $\mathrm{HbA1c}$ correlates with the life cycle of red blood cells. Recent studies suggest that the results of HbAlc are affected by iron deficiency anemia and related with the degree of anemia [9]. 
However, another study finds that iron supplementation during pregnancy does not affect the level of HbAlc and has no clinical effect on the final interpretation of the results in patients with no anemia or mild anemia [10]. High HbA1c and fasting blood glucose levels are believed to significantly alter the relationship between $\mathrm{HbAlc}$, glucose, and age [11]. On the other hand, HbA1c is also considered to be a risk factor for cardiovascular disease in patients [12]. At present, the research on $\mathrm{HbAlc}$ mostly focuses on the control of diabetes and the standard of detection. Many studies believe that $\mathrm{HbA1c}$ is related to many factors, but the results are controversial. Therefore, we designed this study, hoping to clarify the correlation between $\mathrm{HbAlc}$ and other factors through the analysis of big data, such as gender, age, fatty liver, and biochemical indicators, and to further investigate the risk factors affecting $\mathrm{HbAlc}$, in a bid to lay a foundation for the study of HbAlc-related diseases and chronic disease management.

\section{Materials and Methods}

2.1. Data and Methods. This study is a retrospective analysis. People who have been examined in the Health Promotion Center of Sir Run Run Shaw Hospital affiliated with Zhejiang University in Hangzhou in China from July 2018 to June 2019 were selected as the research objects.

Inclusive criteria are the following: (1) detailed medical history collection and (2) completion of examination items in physical examination center.

Exclusion criteria are the following: (1) less than 18 years old, (2) pregnancy or lactation, (3) patients with malignant tumor, (4) patients with liver cirrhosis, (5) patients with chronic kidney disease, (6) patients with heart disease, and (7) patients with autoimmune diseases.

2.2. Clinical and Laboratory Assessments. The medical history was collected by senior general practitioners. The contents of medical history collection include current medical history (existing symptoms, drugs being taken, and so on), past history (operation history, blood transfusion history, past disease history, and so on), and family history. Weight, height, waist circumference, and blood pressure were completed by trained nurses. Body mass index (BMI) was calculated as body weight $(\mathrm{kg}) /$ height squared $\left(\mathrm{m}^{2}\right)$. Serum fasting blood glucose (FBG), total cholesterol (TC), triglyceride (TG), uric acid (UA), aminotransferase (ALT), high-density lipoprotein cholesterol (HDL-C), blood urea nitrogen (BUN), low-density lipoprotein cholesterol (LDL-C), aspartate aminotransferase (AST), and creatinine ( $\mathrm{Cr}$ ) were measured using a Hitachi 7600 clinical analyzer (Hitachi, Tokyo, Japan). Thyroid function including thyroid-stimulating hormone (TSH), free thyroxine (FT4), free triiodothyronine (FT3), thyroid globulin antibody (Tg-Ab), and thyroid peroxidase antibody (TPO-Ab) were quantified by chemiluminescent enzyme immunoassays (ICMA; Abbott, Chicago, IL, USA). The blood sample for laboratory tests was drawn from individuals after $8 \mathrm{~h}$ or more of fasting.
2.3. Diagnostic Criteria. Diagnosis of patients with diabetes: diabetes has been clinically diagnosed with blood glucose more than $7.0 \mathrm{mmol} / \mathrm{I}$ [13] or in the case of oral hypoglycemic drugs assumption. Fatty liver was diagnosed according to the results of $\mathrm{B}$ ultrasound. According to BMI, it was divided into underweight (BMI $<18.5 \mathrm{~kg} / \mathrm{m}^{2}$ ) group, overweight $\left(\mathrm{BMI} \geq 24 \mathrm{~kg} / \mathrm{m}^{2}\right)$ group, and normal weight $\left(18.5 \mathrm{~kg} / \mathrm{m}^{2} \leqq \mathrm{BMI}<24 \mathrm{~kg} / \mathrm{m}^{2}\right)$ group.

2.4. Statistical Analysis. All data were analyzed using the Windows R software (version 3.5.1). This study is a retrospective study using secondary analysis. T-test or MannWhitney $U$ test was used for continuous variable comparison, and chi-square test was used to compare categorical variables. The $t / \chi^{2}$ tests were used to compare the differences between the demographics and characteristics of two groups. The univariate analysis was used to compare the differences between the demographics and characteristics of three or more groups. Multiple linear regression was used to compare the relationship between $\mathrm{HbA} 1 \mathrm{c}$ and gender, age, weight, and other biochemical factors. A multivariate logistic regression model was used to evaluate associated factors with the elevation of HbA1c. In this model, whether HbA1c elevated over $6.5 \%$ was defined as the dependent variables, and factors such as age, sex, fatty liver condition, waist circumference, and systolic blood pressure were defined as the independent variables. The mean of continuous data is expressed as mean \pm SD. $p<0.05$ was statistically significant.

\section{Results}

3.1. Comparison of Baseline Data between Men and Women. Finally, a total of 23,933 subjects were included in this study, including 13,566 men and 10,367 women (Figure 1). There were significant differences between men and women in age, BMI, waist circumference, blood pressure, FBG, blood lipid, thyroid function, liver, and kidney function. Age, BMI, waist circumference, blood pressure, RBC count, and hemoglobin in men were higher than those in women; FBG in men was higher than those in women, glycosylation in men was higher than those in women; blood lipids in men were higher than those in women; liver enzymes in men were higher than those in women; UA in men was higher than those in women; $\mathrm{CR}$ and BUN in men were higher than those in women; thyroxine in men was higher than those in women; thyrotropin in women was higher than those in men; thyroid hormone in women was higher than that of men. The antibody of women was higher than that of men (Table 1).

In the men group, HBA1c of the three groups with different BMI levels were different and showed an upward trend with the increase of BMI $(p \leq 0.01)$. In the men group, HBA1c of the group with no fatty liver was different from that of the group with fatty liver, and HBA1c of the group with fatty liver was higher $(p \leq 0.01)$. In the men group, the proportion of $\mathrm{HbAlc}$ increased in the three groups with different BMI levels was different $(p \leq 0.01)$. In the men group, the proportion of increased $\mathrm{HbAlc}$ in the group with fatty liver was higher $(p \leq 0.01)$. In the women group, glycosylated 


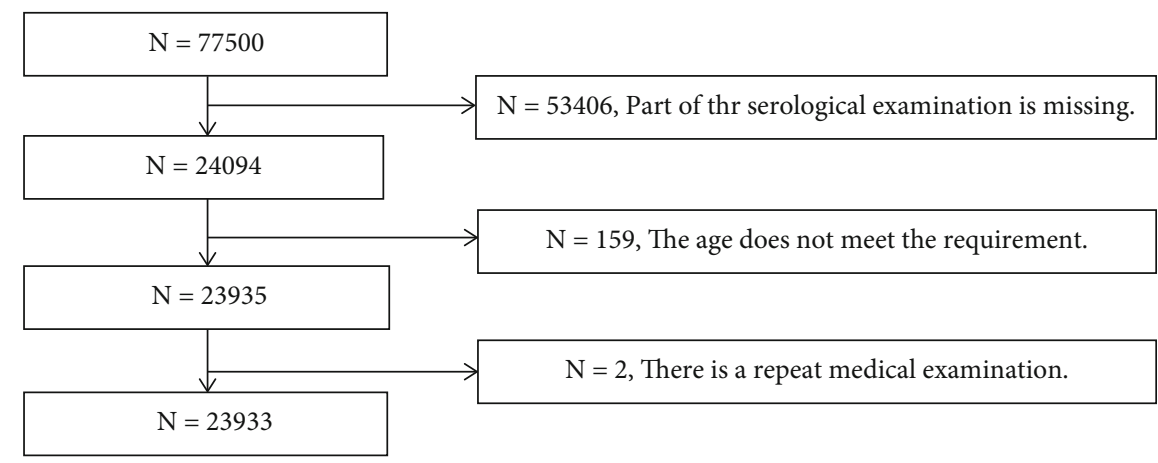

Figure 1: Flow diagram.

TABLE 1: Comparison of baseline data between men and women.

\begin{tabular}{|c|c|c|c|}
\hline & $\begin{array}{c}\text { Women } \\
n=10367\end{array}$ & $\begin{array}{c}\text { Men } \\
n=13566\end{array}$ & $p$ \\
\hline Age & $46.92 \pm 10.54$ & $47.94 \pm 10.32$ & $p \leq 0.01$ \\
\hline BMI & $22.80 \pm 2.99$ & $25.03 \pm 3.10$ & $p \leq 0.01$ \\
\hline WC & $77.27 \pm 8.58$ & $89.20 \pm 8.52$ & $p \leq 0.01$ \\
\hline SBP & $117.44 \pm 17.59$ & $124.91 \pm 15.04$ & $p \leq 0.01$ \\
\hline DBP & $69.00 \pm 10.91$ & $75.59 \pm 10.70$ & $p \leq 0.01$ \\
\hline FBG & $5.14 \pm 0.86$ & $5.50 \pm 1.33$ & $p \leq 0.01$ \\
\hline $\mathrm{RBC}$ & $4.31 \pm 0.35$ & $4.91 \pm 0.40$ & $p \leq 0.01$ \\
\hline $\mathrm{HB}$ & $129.67 \pm 11.40$ & $152.10 \pm 10.32$ & $p \leq 0.01$ \\
\hline HBA1C & $5.38 \pm 0.60$ & $5.56 \pm 0.81$ & $p \leq 0.01$ \\
\hline TG & $1.31 \pm 0.98$ & $1.99 \pm 1.71$ & $p \leq 0.01$ \\
\hline TC & $4.77 \pm 0.93$ & $4.83 \pm 0.94$ & $p \leq 0.01$ \\
\hline $\mathrm{HDL}$ & $1.42 \pm 0.33$ & $1.16 \pm 0.28$ & $p \leq 0.01$ \\
\hline LDL & $2.62 \pm 0.73$ & $2.74 \pm 0.76$ & $p \leq 0.01$ \\
\hline ALT & $18.99 \pm 15.26$ & $31.20 \pm 26.19$ & $p \leq 0.01$ \\
\hline AST & $18.58 \pm 8.41$ & $22.14 \pm 13.42$ & $p \leq 0.01$ \\
\hline UA & $287.27 \pm 59.84$ & $400.56 \pm 78.26$ & $p \leq 0.01$ \\
\hline BUN & $4.56 \pm 1.14$ & $5.06 \pm 1.16$ & $p \leq 0.01$ \\
\hline CR & $57.79 \pm 8.61$ & $80.65 \pm 13.24$ & $p \leq 0.01$ \\
\hline FT3 & $2.80 \pm 0.41$ & $2.97 \pm 0.37$ & $p \leq 0.01$ \\
\hline FT4 & $1.00 \pm 0.12$ & $1.02 \pm 0.11$ & $p \leq 0.01$ \\
\hline TSH & $2.00 \pm 1.47$ & $1.71 \pm 1.44$ & $p \leq 0.01$ \\
\hline TGAB & $25.62 \pm 93.61$ & $7.73 \pm 45.52$ & $p \leq 0.01$ \\
\hline TPOAB & $27.42 \pm 110.39$ & $10.29 \pm 64.41$ & $p \leq 0.01$ \\
\hline
\end{tabular}

Note: BMI: body mass index; WC: waist circumference; SBP: systolic blood pressure; DBP: diastolic blood pressure; FBG: fast blood glucose; HBA1C: glycated hemoglobin; TC: total cholesterol; TG: triglycerides; LDL: lowdensity lipoprotein; HDL: high-density lipoprotein; ALT: alanine aminotransferase; AST: Aspartate aminotransferase; UA: serum uric acid; BUN: blood urea nitrogen; CR: creatinine; FT3: free Triiodothyronine; FT4: free thyroxine; TSH: thyroid-stimulating hormone; TGAB: thyroid peroxidase antibody; TPOAB: thyroglobulin antibody. $p<0.05$ was considered statistically significant. hemoglobin of the three groups with different BMI levels was different and showed an upward trend with the increase of BMI $(p \leq 0.01)$. In the women group, HbA1c was higher in the group with fatty liver $(p \leq 0.01)$. In the women group, the proportion of $\mathrm{HbAlc}$ increased in the three groups with different BMI levels was different $(p \leq 0.01)$. In the men group, the proportion of HbA1c increased in the group with fatty liver was higher $(p \leq 0.01)$.

3.2. Comparison of Baseline Data between Group with Diabetes and Group with No Diabetes. The included samples were divided into group with diabetes and group with no diabetes (Table 2). There were significant differences in age, BMI, waist circumference, blood pressure, FBG, blood lipid, thyroid function, and renal function between group with diabetes and group with no diabetes, but there were no significant differences in AST and TGAb. The age, BMI, waist circumference, blood pressure, RBC count, hemoglobin, fasting FBG, glycosylation, TG, LDL, ALT, UA, CR, and BUN of group with diabetes were lower than those of group with no diabetes. The levels of TC, HDL, FT3, TSH, TGAb, and $\mathrm{TPOAb}$ in group with diabetes were higher than those in group with no diabetes.

In the group with no diabetes, the HbAlc of the three groups with different BMI levels were different and showed an upward trend $(p \leq 0.01)$. In the group with no diabetes, HbAlc of group with fatty liver was higher $(p \leq 0.01)$. In the group with no diabetes, the proportion of HbAlc increased was different among the three groups with different BMI levels $(p \leq 0.01)$. In the group with no diabetes, the proportion of $\mathrm{HbAlc}$ increased in the group with fatty liver was higher $(p \leq 0.01)$. In the group with diabetes, HbAlc of the three groups with different BMI levels was the same $(p=0.8)$. In the group with diabetes, HbAlc of group with fatty liver was higher $(p \leq 0.01)$. In the group with diabetes, the proportion of people with elevated HbAlc was the same among the three groups with different BMI levels $(p=0.341)$. In the group with no diabetes, the proportion of $\mathrm{HbAlc}$ increased in the group with fatty liver was higher $(p \leq 0.01)$.

3.3. Correlation between HbAlc and Body Weight. According to BMI, the samples of group with diabetes and group with no diabetes were divided into three groups: group with underweight, group with normal weight, and group with overweight. Analysis of variance showed that HbAlc 
TABLE 2: Comparison of baseline data between diabetes group and nondiabetes group.

\begin{tabular}{|c|c|c|c|}
\hline & $\begin{array}{c}\text { Nondiabetes group } \\
\qquad n=22720\end{array}$ & $\begin{array}{c}\text { Diabetes group } \\
\quad n=1213\end{array}$ & $p$ \\
\hline Age & $47.09 \pm 10.36$ & $55.04 \pm 8.76$ & $p \leq 0.01$ \\
\hline Male sex & $12645(55.7 \%)$ & $921(75.9 \%)$ & $p \leq 0.01$ \\
\hline BMI & $23.99 \pm 3.24$ & $25.49 \pm 3.06$ & $p \leq 0.01$ \\
\hline WC & $83.68 \pm 10.33$ & $90.75 \pm 9.08$ & $p \leq 0.01$ \\
\hline SBP & $121.30 \pm 16.54$ & $128.80 \pm 16.24$ & $p \leq 0.01$ \\
\hline DBP & $72.58 \pm 11.31$ & $75.58 \pm 10.16$ & $p \leq 0.01$ \\
\hline FBG & $5.21 \pm 0.85$ & $7.94 \pm 2.46$ & $p \leq 0.01$ \\
\hline HBA1C & $5.39 \pm 0.57$ & $7.11 \pm 1.33$ & $p \leq 0.01$ \\
\hline TG & $1.68 \pm 1.45$ & $2.09 \pm 1.91$ & $p \leq 0.01$ \\
\hline $\mathrm{TC}$ & $4.81 \pm 0.93$ & $4.66 \pm 1.06$ & $p \leq 0.01$ \\
\hline HDL & $1.27 \pm 0.32$ & $1.16 \pm 0.29$ & $p \leq 0.01$ \\
\hline LDL & $2.69 \pm 0.75$ & $2.53 \pm 0.81$ & $p \leq 0.01$ \\
\hline ALT & $25.75 \pm 22.99$ & $29.04 \pm 21.86$ & $p \leq 0.01$ \\
\hline AST & $20.57 \pm 11.43$ & $20.98 \pm 15.22$ & 0.326 \\
\hline UA & $350.97 \pm 90.68$ & $361.21 \pm 84.65$ & $p \leq 0.01$ \\
\hline BUN & $4.82 \pm 1.16$ & $5.34 \pm 1.41$ & $p \leq 0.01$ \\
\hline CR & $70.68 \pm 16.00$ & $72.02 \pm 18.13$ & 0.011 \\
\hline FT3 & $2.90 \pm 0.40$ & $2.81 \pm 0.36$ & $p \leq 0.01$ \\
\hline FT4 & $1.01 \pm 0.11$ & $1.03 \pm 0.12$ & $p \leq 0.01$ \\
\hline TSH & $1.84 \pm 1.48$ & $1.71 \pm 1.12$ & $p \leq 0.01$ \\
\hline TGAB & $15.75 \pm 71.73$ & $10.56 \pm 56.69$ & $p \leq 0.01$ \\
\hline ТРОАВ & $17.94 \pm 88.22$ & $13.49 \pm 78.19$ & 0.055 \\
\hline
\end{tabular}

Note: BMI: body mass index; WC: waist circumference; SBP: systolic blood pressure; DBP: diastolic blood pressure; FBG: fast blood glucose; HBA1C: glycated hemoglobin; TC: total cholesterol; TG: triglycerides; LDL: lowdensity lipoprotein; HDL: high-density lipoprotein; ALT: alanine aminotransferase; AST: aspartate aminotransferase; UA: serum uric acid; BUN: blood urea nitrogen; CR: creatinine; FT3: free triiodothyronine; FT4: free thyroxine; TSH: thyroid-stimulating hormone; TGAB: thyroid peroxidase antibody; TPOAB: thyroglobulin antibody. $p<0.05$ was considered statistically significant.

increased with weight gain in group with no diabetes, but not in group with diabetes. (Table 3 ).

3.4. Correlation between HbAlc and Fatty Liver. Fatty liver was diagnosed according to the results of B-ultrasound. Group with diabetes and group with no diabetes were divided into two groups: fatty liver and no fatty liver. In the group with no diabetes, there were 7,659 patients in the group with fatty liver and 15,061 people in the group with no fatty liver. The HbAlc in the group with fatty liver was significantly higher than that in the group with no fatty liver $(5.58 \pm 0.72$ vs. $5.29 \pm 0.44)$. In the group with diabetes, there were 763 patients in the group with fatty liver and 450 people in the group with no fatty liver. In the group with diabetes, the $\mathrm{HbAlc}$ in the group with fatty liver was significantly higher than that in the group with no fatty liver $(7.20 \pm 1.24$ vs. $6.97 \pm 1.45)$.
3.5. Linear Correlation Analysis of HbA1c. The results of multiple linear regression analysis showed that $\mathrm{HbAlc}$ had linear correlation with age, gender (men), fatty liver, SBP, RBC, hemoglobin, TC, HDLC, LDLC, UA, BUN, FT3, and FT4.

3.6. The Correlation between the Increase of HbAlc (>6.5\%) and Diabetes Mellitus, Fatty Liver, and Body Weight. The results of chi-square analysis showed that HbAlc increased more in group with diabetes $(792 / 1213)$ than in group with no diabetes $(653 / 22720)(p<0.05)$.

Fisher's exact test showed that in the group with no diabetes, there was difference in the proportion of patients with elevated $\mathrm{HbAlc}$ in the group with underweight $(3 / 683)$, the group with normal weight (135/11172), and the group with overweight (515/10865). The proportion of patients with high HbAlc increased with the increase of body weight. There was no difference in the proportion of patients with elevated $\mathrm{HbAlc}$ in group with diabetes (group with underweight (5/9), group with normal weight (245/390), and group with overweight (542/814)).

Chi-square analysis showed that in the group with no diabetes, the proportion of HbAlc in the group with fatty liver (513/7659) was significantly higher than that in the group with no fatty liver (140/15061). In group with diabetes, the proportion of $\mathrm{HbAlc}$ increased significantly in the group with fatty liver $(529 / 763)$ than that in the group with no fatty liver (263/450).

3.7. Logistic Regression Analysis of Risk Factors for Elevated $H b A 1 c$. Finally, the logistic model was statistically significant. In the model, age, gender (men), fatty liver, waist circumference, SBP, RBC number, hemoglobin, blood lipid (TG, HDLC), UA, BUN, Cr, FT3, and FT4 were statistically significant. The results showed that the risk of elevated HbAlc increased by $6.7 \%$ for each year of age increase. The risk of elevated HbAlc was 2.45 times higher in men than in women. Compared with patients without fatty liver, patients with fatty liver had a two-fold increased risk of HbAlc. For every $1 \mathrm{~cm}$ increase in waist circumference, the risk of elevated $\mathrm{HbAlc}$ increased by $5.7 \%$. For each unit of SBP increase, the risk of elevated $\mathrm{HbA} 1 \mathrm{c}$ increased by $0.9 \%$. When the number of RBC increased by $1 \times 10^{12}$, the risk of elevated $\mathrm{HbA} 1 \mathrm{c}$ increased by $53.9 \%$. For every $1 \mathrm{~g} / \mathrm{L}$ increase in hemoglobin, the risk of elevated HbAlc decreased by $0.9 \%$. For each unit of TG increase, the risk of elevated $\mathrm{HbAlc}$ increased by $10.2 \%$. For each additional unit of HDLC, the risk of elevated $\mathrm{HbAlc}$ decreased by $48.0 \%$. For each unit of UA increase, the risk of elevated $\mathrm{HbAlc}$ decreased by $0.5 \%$. For each unit of BUN increase, the risk of elevated $\mathrm{HbAlc}$ increased by $26.5 \%$. For each unit of $\mathrm{Cr}$ increase, the risk of elevated HbA1c decreased by $3.4 \%$. When FT3 increased by each unit, the risk of elevated $\mathrm{HbAlc}$ decreased by $58.0 \%$. The risk of elevated HbAlc increased by 5.758 times for each unit of FT4 (Table 4).

\section{Discussion}

The results indicate that differences exist in baseline and biochemical indexes between men and women, and the HbAlc 
TABLE 3: Correlation between HbA1c and body weight.

\begin{tabular}{|c|c|c|c|c|}
\hline $\begin{array}{l}\text { Nondiabetes } \\
\text { group }\end{array}$ & $\begin{array}{c}\text { Underweight }\left(\mathrm{BMI}<18.5 \mathrm{~kg} / \mathrm{m}^{2}\right) \\
\qquad N=683\end{array}$ & $\begin{array}{c}\text { Normal weight }\left(18.5 \mathrm{~kg} / \mathrm{m}^{2} \leqq \mathrm{BMI}<24 \mathrm{~kg} / \mathrm{m}^{2}\right) \\
N=11172\end{array}$ & $\begin{array}{c}\text { Overweight }\left(\mathrm{BMI} \geq 24 \mathrm{~kg} / \mathrm{m}^{2}\right) \\
N=10865\end{array}$ & $p$ \\
\hline Hba1c & $5.17 \pm 0.38$ & $5.29 \pm 0.47$ & $5.51 \pm 0.64$ & $p \leq 0.01$ \\
\hline $\begin{array}{l}\text { Diabetes } \\
\text { group }\end{array}$ & $\begin{array}{c}\text { Underweight }\left(\mathrm{BMI}<18.5 \mathrm{~kg} / \mathrm{m}^{2}\right) \\
\qquad N=9\end{array}$ & $\begin{array}{c}\text { Normal weight }\left(18.5 \mathrm{~kg} / \mathrm{m}^{2} \leqq \mathrm{BMI}<24 \mathrm{~kg} / \mathrm{m}^{2}\right) \\
N=390\end{array}$ & $\begin{array}{c}\text { Overweight }\left(\mathrm{BMI} \geq 24 \mathrm{~kg} / \mathrm{m}^{2}\right) \\
\qquad N=814\end{array}$ & $p$ \\
\hline Hbalc & $7.00 \pm 2.15$ & $7.08 \pm 1.45$ & $7.13 \pm 1.26$ & 0.778 \\
\hline
\end{tabular}

Note: BMI: body mass index; analysis of variance was used.

TABLE 4: Logistic regression analysis of risk factors for elevated HbA1c.

\begin{tabular}{lcccccccc}
\hline & Age & MALE & $\begin{array}{c}\text { Fatty } \\
\text { liver }\end{array}$ & Wc & sbp & TG & HDLC & UA \\
\hline OR & 1.067 & 3.448 & 3.002 & 1.057 & 1.009 & 1.102 & 0.520 & 0.995 \\
$p$ & $\leq 0.01$ & $\leq 0.01$ & $\leq 0.01$ & $\leq 0.01$ & $\leq 0.01$ & $\leq 0.01$ & $\leq 0.01$ & $\leq 0.01$ \\
& Bun & Cr & Ft3 & Ft4 & RBC & HB & & \\
OR & 1.265 & 0.966 & 0.420 & 6.758 & 1.539 & 0.991 & & \\
$p$ & $\leq 0.01$ & $\leq 0.01$ & $\leq 0.01$ & $\leq 0.01$ & $\leq 0.01$ & $\leq 0.01$ & & \\
\hline
\end{tabular}

Note: BMI: body mass index; WC: waist circumference; SBP: systolic blood pressure; DBP: diastolic blood pressure; FBG: fast blood glucose; HBA1C: glycated hemoglobin; TC: total cholesterol; TG: triglycerides; LDL: lowdensity lipoprotein; HDL: high-density lipoprotein; ALT: alanine aminotransferase; AST: aspartate aminotransferase; UA: serum uric acid; BUN: blood urea nitrogen; CR: creatinine; FT3: free triiodothyronine; FT4: free thyroxine; TSH: thyroid-stimulating hormone; TGAB: thyroid peroxidase antibody; TPOAB: thyroglobulin antibody. $p<0.05$ was considered statistically significant. $\mathrm{OR}>1$ is risk factor; $\mathrm{OR}<1$ is protective factor.

of men is significantly higher than that of women. A recent study suggests that the HbAlc of men is higher than that of women in the age of 20-59 [14], while the average age of the sample included in this study is $47.94 \pm 10.32$, so the results are consistent with it. Previous studies [15] have also suggested that age and gender should be taken into account in the diagnosis of diabetes with $\mathrm{HbAlc}$, which shows that there is a correlation between gender and HbAlc. Similarly, this study finds that HbAlc is significantly higher in patients with diabetes than patients with no diabetes. For patients with no diabetes, HbAlc increased with the increase of body weight, while in group with diabetes, there was no significant correlation between weight and HbAlc. Compared with patients with no fatty liver, the HbAlc of patients with fatty liver is higher regardless of whether they have diabetes or not. Studies suggest that $\mathrm{HbAlc}$ has low sensitivity and high specificity in the diagnosis of diabetes and prediabetes, which varies with age and race [16]. Therefore, HbAlc may be affected by many factors.

HbAlc level is recommended by the American Diabetes Association (ADA) to be used as an index for the diagnosis of diabetes [17], and it can reflect blood glucose level of 2-3 months. It is suggested that $\mathrm{HbAlc}$ can be used in the diagnosis of diabetes [18]. HbAlc is becoming more and more popular among primary care providers because it has many practical advantages, including convenient sampling, suitable as an indicator of chronic abnormal blood glucose, low individual variation, and favorable laboratory standardization
[19]. In 2010, ADA proposed that HbAlc value of 5.7\%$6.4 \%$ can be diagnosed as prediabetes and $\mathrm{HbA} 1 \mathrm{c} \geq 6.5 \%$ can be diagnosed as diabetes [13], which is a criteria for diagnosis recommended by ADA. In our physically examined population, patients with diabetes included drug users and nondrug users, and $\mathrm{HbAlc}$, as an important indicator of blood glucose management, can show that patients with diabetes in physically examined population do not control blood glucose well.

A recent study suggested that fatty liver is associated with insulin resistance, and $\mathrm{HbAlc}$ in group with fatty liver is significantly higher than that in group with no fatty liver [20], which is consistent with our results. With regard to metabolic risk, nonalcoholic fatty liver disease (NAFLD) is a powerful and highly prevalent predictor of type 2 diabetes [21]. A domestic study suggests that serum $\mathrm{HbAlc}$ level is associated with NAFLD, and the increase of serum $\mathrm{HbAlc}$ level is an independent risk factor for NAFLD in Chinese elderly [22]. Therefore, patients with fatty liver need to be alert to diabetes, and conversely, according to our research, patients with fatty liver have elevated HbAlc. Thus, for those with elevated $\mathrm{HbAlc}$ found in physical examination, doctors should not only pay attention to diabetes but also pay attention to fatty liver. The researchers suggest that NAFLD may transform into liver cancer, which is an important risk factor for it. Therefore, the correlation between HbAlc and fatty liver deserves the attention of doctors. Another study finds that $\mathrm{HbA1c}$ is significantly related to BMI and waist circumference [23], which is consistent with the results of our study on the increase of $\mathrm{HbAlc}$ with weight gain in patients with no diabetes, but it is inconsistent with the results of group with diabetes, which may be due to the small sample size.

At present, the research on the relationship between age and $\mathrm{HbAlc}$ is still limited. Studies have confirmed that $\mathrm{HbA1c}$ increases with age in individuals with no diabetes [24]. Some studies have found that the diagnostic efficiency of $\mathrm{HbAlc}$ for diabetes decreases with age, which is caused by the decrease of RBC count with age [25]. For adolescents and children, the study finds that $\mathrm{HbAlc}$ level decreased every 100 percentile from 2 to 4 years old, increased gradually before puberty, reached the peak at 12 to 14 years old, and then dropped to the lowest level in the third decade [26]. The results of this study suggest that the risk of elevated $\mathrm{HbAlc}$ increases by $6.7 \%$ for each year of age increase. In view of the correlation between gender, fatty liver, waist circumference, and HbAlc, this study also finds that men, fatty liver, and waist circumference increase the risk of elevated HbAlc. In the study of type 1 diabetes, it is found that 
HbA1c, night heart rate, and height were related to blood pressure changes [27]. Studies also suggest that elevated blood pressure has contributed to the increase in incidence rate of stroke, which is related to elevated blood glucose level represented by HbAlc [28]. This study finds that for each unit of SBP increase, the risk of elevated $\mathrm{HbAlc}$ increased by $0.9 \%$. Iron deficiency anemia can affect the homeostasis of glucose and the control of blood glucose [29]. The mechanism is that iron deficiency accelerates glycosylation by changing the structure of hemoglobin and inducing peroxidation [30]. It can be seen that hemoglobin is related to HbA1c.

A cross-sectional study shows that HbA1c is significantly correlated with serum TC, TG, and HDLC levels in patients with diabetes, but not with LDLC [31]. One study finds that TC and abnormal LDL-C values of patients with HbA1c $\geq 7.0 \%$ were significantly higher than those of patients with HbAlc $<7.0 \%$ [32]. At the same time, studies on patients with type 2 diabetes have found that serum uric acid concentration is associated with microalbuminuria and glycosylated hemoglobin [33]. These results are consistent with our results, and our study further found that the risk of elevated $\mathrm{HbA} 1 \mathrm{c}$ increased by $10.2 \%$ for each unit of TG and decreased by $48.0 \%$ for each unit of HDLC. UA is considered to be related to HbA1c level [34]. Our study suggests that for each unit of UA increase, the risk of elevated HbAlc decreases by $0.5 \%$. Similarly, a recent study finds that UA is negatively correlated with $\mathrm{HbA} 1 \mathrm{c}$ in newly diagnosed patients with diabetes but is associated with hyperinsulinemia. If insulin is used, UA and HbA1c are not significantly correlated [35]. Besides, low serum creatinine is considered to be associated with an increased risk of diabetes, and screening serum creatinine levels can be used to identify high-risk groups of diabetes [36]. Our study suggests that the risk of elevated HbA1c decreases by $3.4 \%$ for each unit of $\mathrm{Cr}$ increase, which is consistent with the literature results. The incidence of thyroid dysfunction in patients with type 2 diabetes is higher and increased with the increase of HBA1c [37]. This may explain the correlation between thyroid hormone and HbAlc. However, we have not been able to find the research related to policy. Therefore, we hope our research can exert important significance for the early screening of diseases.

\section{Strengths and Limitations}

The advantage of our research lies in the large sample size, the samples are from the same hospital's health promotion center, and the data has the characteristics of authenticity and objectivity. However, there are still some limitations in this study: (1) the diagnosis of diabetes mellitus is only based on the medical history; (2) the included samples in the group with diabetes do not distinguish drug assumptions or not; (3) this study is a cross-sectional study, which can only explain the results of a certain level, but cannot reflect the changes in a period of time; (4) it is impossible to make a clear and detailed history of drinking; (5) the diagnosis of fatty liver is only based on the results of B ultrasound; (6) it is impossible to distinguish whether the sample population is carrying out lifestyle intervention. We hope to design prospective studies or clinical controlled trials in the future and confirm the relevant research conclusions through more data. On this basis, we will try our best to eliminate interference factors and establish clinical controlled trials to clarify the correlation between various metabolic diseases and HbAlc.

\section{Conclusion}

This study found that HbA1c levels are not only associated with diabetes but also with a variety of other metabolic factors. HbAlc is associated with body weight in population with no diabetes. The level of HbAlc in patients with fatty liver is higher than that in patients with no fatty liver. In addition, HbA1c level is linearly correlated with body weight, SBP, fatty liver, gender, age, blood lipid, thyroid hormone, $\mathrm{UA}$, and renal function. Therefore, the increase of HbAlc may be related to many diseases and abnormal biochemical indexes. It is suggested that clinicians need to screen other metabolic diseases when HbAlc is abnormal in physical examination, which will be conducive to the development of clinical health management and early screening of diseases. In conclusion, $\mathrm{HbAlc}$ is associated with many metabolic indicators, which can be further developed as a special marker for early screening of chronic diseases.

\section{Data Availability}

The data used to support the findings of this study are available from the corresponding author upon request.

\section{Conflicts of Interest}

There is no conflict of interest.

\section{Acknowledgments}

This research was supported by the National Natural Science Foundation of China (82074214, 81973598, 81573760), Zhejiang Provincial Natural Science Foundation of China under Grant No.LY18H030001, Medicine and Health Science and Technology Plan Projects in Zhejiang province (2017KY413), Traditional Chinese Medicine Science and Technology Plan of Zhejiang Province (2017ZA089, 2016ZB071, 2015ZZ012, 2014ZA030), Medical Health Platform Plan Projects of Zhejiang Province (2015RCA020), and Zhejiang Provincial Natural Science Foundation of China (LY16H030010).

\section{References}

[1] A. M. Schmidt, "Highlighting diabetes mellitus: the epidemic continues," Arteriosclerosis, Thrombosis, and Vascular Biology, vol. 38, no. 1, pp. e1-e8, 2018.

[2] The Lancet, "Diabetes: a dynamic disease," Lancet, vol. 389, no. 10085 , p. $2163,2017$.

[3] D. B. Utami and A. Findyartini, "Plant-based diet for HbA1c reduction in type 2 diabetes mellitus: an evidence-based case report," Acta Medica Indonesiana, vol. 50, no. 3, pp. 260$267,2018$. 
[4] O. Schnell, J. B. Crocker, and J. Weng, "Impact of HbAlc testing at point of care on diabetes management," Journal of Diabetes Science and Technology, vol. 11, no. 3, pp. 611-617, 2017.

[5] G. Li, L. Han, Y. Wang et al., "Evaluation of ADA HbA1c criteria in the diagnosis of pre-diabetes and diabetes in a population of Chinese adolescents and young adults at high risk for diabetes: a cross-sectional study," BMJ Open, vol. 8, no. 8, article e020665, 2018.

[6] W. Fan, H. Zheng, N. Wei, and D. M. Nathan, "Estimating HbA1c from timed self-monitored blood glucose values," Diabetes Research and Clinical Practice, vol. 141, pp. 56-61, 2018.

[7] R. Rajput, YogeshYadav, M. Rajput, and S. Nanda, "Utility of HbA1c for diagnosis of gestational diabetes mellitus," Diabetes Research and Clinical Practice, vol. 98, no. 1, pp. 104-107, 2012.

[8] N. Wayne, D. F. Perez, D. M. Kaplan, and P. Ritvo, "Health coaching reduces $\mathrm{HbAlc}$ in type 2 diabetic patients from a lower-socioeconomic status community: a randomized controlled trial," Journal of Medical Internet Research, vol. 17, no. 10, article e224, 2015.

[9] J. F. Silva, A. L. Pimentel, and J. L. Camargo, "Effect of iron deficiency anaemia on $\mathrm{HbAlc}$ levels is dependent on the degree of anaemia," Clinical Biochemistry, vol. 49, no. 1-2, pp. 117-120, 2016.

[10] P. B. Renz, M. K. Hernandez, and J. L. Camargo, "Effect of iron supplementation on $\mathrm{HbAlc}$ levels in pregnant women with and without anaemia," Clinica Chimica Acta, vol. 478, pp. 57-61, 2018.

[11] L. Feng, S. Nian, Y. Zhao et al., "Higher HbA1c and/or glucose levels alter the association patterns between glycated hemoglobin and fasting glucose levels," Diabetes Research and Clinical Practice, vol. 142, pp. 353-362, 2018.

[12] B. Kowall, "HbA1c target goals in type-2 diabetes: novel arguments from measurement of coronary artery calcification," International Journal of Cardiology, vol. 266, pp. 256-257, 2018.

[13] American Diabetes Association, "Diagnosis and classification of diabetes mellitus," Diabetes Care, vol. 33, Supplement_1, pp. S62-S69, 2010.

[14] J. Hu, J. Gao, and J. Li, "Sex and age discrepancy of HbAlc and fetal hemoglobin determined by HPLC in a large Chinese Han population," Journal of diabetes, vol. 10, no. 6, pp. 458-466, 2018.

[15] M. Inoue, K. Inoue, and K. Akimoto, "Effects of age and sex in the diagnosis of type 2 diabetes using glycated haemoglobin in Japan: the Yuport Medical Checkup Centre study," PLoS One, vol. 7, no. 7, article e40375, 2012.

[16] F. Guo, D. R. Moellering, and W. T. Garvey, "Use of HbA1c for diagnoses of diabetes and prediabetes: comparison with diagnoses based on fasting and 2-Hr glucose values and effects of gender, race, and age," Metabolic Syndrome and Related Disorders, vol. 12, no. 5, pp. 258-268, 2014.

[17] I. Cavero-Redondo, B. Peleteiro, C. Álvarez-Bueno, F. Rodriguez-Artalejo, and V. Martínez-Vizcaíno, "Glycated haemoglobin A1c as a risk factor of cardiovascular outcomes and all-cause mortality in diabetic and non-diabetic populations: a systematic review and meta-analysis," BMJ Open, vol. 7, no. 7, article e015949, 2017.

[18] N. Y. Kim, J. An, J. K. Jeong et al., "Evaluation of a human glycated hemoglobin test in canine diabetes mellitus," Journal of
Veterinary Diagnostic Investigation, vol. 31, no. 3, pp. 408414, 2019.

[19] S. S. Fajans, W. H. Herman, and E. A. Oral, "Insufficient sensitivity of hemoglobin $\mathrm{A}_{1 \mathrm{C}}$ determination in diagnosis or screening of early diabetic states," Metabolism, vol. 60, no. 1, pp. 86-91, 2011.

[20] J. M. Han, H. I. Kim, Y. J. Lee, J. W. Lee, K. M. Kim, and J. C. Bae, "Differing associations between fatty liver and dyslipidemia according to the degree of hepatic steatosis in Korea," Journal of Lipid and Atherosclerosis, vol. 8, no. 2, pp. 258266, 2019.

[21] M. Wargny, S. Smati, M. Pichelin et al., "Fatty liver index is a strong predictor of changes in glycemic status in people with prediabetes: the IT-DIAB study," PLoS One, vol. 14, no. 8, article e0221524, 2019.

[22] H. Ma, C. Xu, L. Xu, C. Yu, M. Miao, and Y. Li, "Independent association of $\mathrm{HbAlc}$ and nonalcoholic fatty liver disease in an elderly Chinese population," BMC gastroenterology, vol. 13, no. 1, 2013.

[23] M. Mataftsi, G. Koukos, and D. Sakellari, "Prevalence of undiagnosed diabetes and pre-diabetes in chronic periodontitis patients assessed by an HbAlc chairside screening protocol," Clinical Oral Investigations, vol. 23, no. 12, pp. 4365-4370, 2019.

[24] A. Masuch, N. Friedrich, J. Roth, M. Nauck, U. A. Müller, and A. Petersmann, "Preventing misdiagnosis of diabetes in the elderly: age-dependent $\mathrm{HbAlc}$ reference intervals derived from two population-based study cohorts," BMC endocrine disorders, vol. 19, no. 1, p. 20, 2019.

[25] L. Wu, H. Lin, J. Gao et al., "Effect of age on the diagnostic efficiency of HbAlc for diabetes in a Chinese middle-aged and elderly population: the Shanghai Changfeng Study," PLoS One, vol. 12, no. 9, article e0184607, 2017.

[26] O. Pinhas-Hamiel, U. Hamiel, V. Boyko, C. Graph-Barel, B. Reichman, and L. Lerner-Geva, "Trajectories of HbAlc levels in children and youth with type 1 diabetes," PLoS One, vol. 9, no. 10, article e109109, 2014.

[27] T. B. Torbjornsdotter, G. A. Jaremko, and U. B. Berg, "Ambulatory blood pressure and heart rate in relation to kidney structure and metabolic control in adolescents with type I diabetes," Diabetologia, vol. 44, no. 7, pp. 865-873, 2001.

[28] On behalf of Iwate-Kenco Study Group, R. Komi, F. Tanaka et al., "Burden of high blood pressure as a contributing factor to stroke in the Japanese community-based diabetic population," Hypertension Research, vol. 41, no. 7, pp. 531-538, 2018.

[29] A. T. Soliman, V. De Sanctis, M. Yassin, and N. Soliman, "Iron deficiency anemia and glucose metabolism," Acta Bio-Medica, vol. 88, no. 1, pp. 112-118, 2017.

[30] W. Guo, Q. Zhou, Y. Jia, and J. Xu, "Increased levels of glycated hemoglobin A1c and iron deficiency anemia: a review," Medical Science Monitor, vol. 25, pp. 8371-8378, 2019.

[31] A. Begum, S. R. Irfan, M. R. Hoque et al., "Relationship between $\mathrm{HbA1c}$ and lipid profile seen in Bangladeshi type 2 diabetes mellitus patients attending BIRDEM hospital: a cross-sectional study," Mymensingh Medical Journal, vol. 28, no. 1, pp. 91-95, 2019.

[32] M. J. Shahwan, A. A. Jairoun, A. Farajallah, and S. Shanabli, "Prevalence of dyslipidemia and factors affecting lipid profile in patients with type 2 diabetes," Diabetes and Metabolic Syndrome: Clinical Research and Reviews, vol. 13, no. 4, pp. 23872392, 2019. 
[33] S. Neupane, R. K. Dubey, N. Gautam et al., "Association between serum uric acid, urinary albumin excretion, and glycated hemoglobin in type 2 diabetic patient," Nigerian Medical Journal, vol. 57, no. 2, pp. 119-123, 2016.

[34] M. Ouchi, K. Oba, K. Kaku et al., "Uric acid lowering in relation to HbA1c reductions with the SGLT2 inhibitor tofogliflozin," Diabetes, Obesity \& Metabolism, vol. 20, no. 4, pp. 1061-1065, 2018.

[35] Y. Cui, H. Bu, X. Ma, S. Zhao, X. Li, and S. Lu, "The relation between serum uric acid and $\mathrm{HbAlc}$ is dependent upon hyperinsulinemia in patients with newly diagnosed type 2 diabetes mellitus," Journal Diabetes Research, vol. 2016, article 7184123, pp. 1-6, 2016.

[36] H. Hu, T. Nakagawa, T. Honda et al., "Low serum creatinine and risk of diabetes: the Japan epidemiology collaboration on occupational health study," Journal of diabetes investigation, vol. 10, no. 5, pp. 1209-1214, 2019.

[37] E. H. Elgazar, N. E. Esheba, S. A. Shalaby, and W. F. Mohamed, "Thyroid dysfunction prevalence and relation to glycemic control in patients with type 2 diabetes mellitus," Diabetes and Metabolic Syndrome: Clinical Research and Reviews, vol. 13, no. 4, pp. 2513-2517, 2019. 